\title{
TOXIC ACTION OF ACID SODIUM SALTS ON LUPINUS ALBUS
}

BY LOUIS KAHLENBERG AND ROLLAN M. AUSTIN.

The toxic action of solutions of acids, salts, and bases upon Lupinus albus has been the subject of previous investigations. ${ }^{x}$ The general result obtained, when stated in terms of the theory of electrolytic dissociation, is that the toxicity of a solution is equal to the sum of the poisonous properties of the ions. and the undissociated molecules present. Hydrogen ions were found to have a strongly toxic action, a solution containing I/6400 gram hydrogen ions per liter just permitting seedlings of Lupinus albus to survive. With the exception of acid potassium sulphate and acid potassium oxalate, no solutions of acid salts have been tested in the researches mentioned, as to their poisonous properties on plants. As the degree of hydrogen dissociation of acid sodium salts has been carefully investigated by means of the method of sugar inversion, ${ }^{2}$ and as the coefficients of dissociation have been found to be surprisingly small, it was thought to be of interest to ascertain the toxic effects of solutions of acid sodium salts on Lupinus albus and to compare the results obtained with the coefficients of hydrogen dissociation. In this way an additional test of the applicability of the theory of electrolytic dissociation to the physiological phenomena in question would be secured.

Briefly stated, the method of experimentation consisted in raising seedlings of Lupinus albus having radicles of from $2 \mathrm{~cm}$ to $4 \mathrm{~cm}$ long. Fifteen millimeters from the tip of each root a fine

${ }^{1}$ Kahlenberg and True. Botanical Gazette, 22, 8I (1896). Heald. Ibid. 22, I25 (1896). True. Amer. Jour. Sci. 9, I83 (1900).

2 J. E. Trevor. Zeit. phys. Chem. I0, 32 (1892). Also W. A. Smith. Zeit. phys. Chem. 25, 21 7 (1898). 
mark was made with India ink. These seedlings were then suspended in the solution to be tested, so that the root, - and this only, - was immersed. After about 24 hours the seedlings were measured and their general condition was noted. In cases where it was doubtful as to whether the plant was dead or alive, the latter was returned to the solution and measured again later. The object of the whole procedure was to ascertain as nearly as possible the strength of the solution in which the seedlings would just survive. It is, of course, not possible to determine this strength to a high degree of accuracy as some seedlings, even when taken from the same lot, are more hardy and resistant than others. A fair degree of approximation, however, can be reached by testing several seedlings in each solution and by performing several series of tests with different lots of beans. A comparison of the results tabulated below will give an idea of the relative accuracy that may be obtained in experiments of this kind. This short description of the experimental method employed may here suffice as a more detailed one has already been publislied. ${ }^{\mathrm{r}}$

The toxic action of acids and acid salts is best compared with that of hydrochloric acid, which, at the high dilution in which the seedlings just survive, is practically completely dissociated according to the dissociation theory. It is evident therefore that it is highly desirable to determine as accurately as possible this particular critical concentration for hydrochloric acid. In the previous researches, ${ }^{2}$ the successive solutions tested differed in strength in that each was one-half as concentrated as the next preceding one. It is clear that by testing solutions that vary less in concentration, the critical strength sought might be more accurately ascertained. Accordingly, solutions of hydrochloric acid of suitable concentration were prepared and tested with seedlings of Lupinus albus. Four series of experiments were performed. The results are given in Table I.

${ }^{1}$ Kahlenberg and True. 1. c. ; also Heald. 1. c.

21. c. 
TABLE I

Hydrochloric Acid

(Begun Feb. 16, I I.20 a.m.; closed Fieb. 17, 9.25 a.m.)

\begin{tabular}{|c|c|c|}
\hline $\begin{array}{l}\text { Concentration } \\
\text { gm. mol. per liter }\end{array}$ & Length & Remarks \\
\hline $1 / 3200$ & $16 \mathrm{~mm}$ & $\underset{:}{\text { dead, flabby }}$ \\
\hline '، & I $7 \approx$ & " \\
\hline " & I 7 " & “ \\
\hline $1 / 4000$ & $16 "$ & “ \\
\hline "، & $16 "$ & ، \\
\hline " & I $7 \cdots$ & ، \\
\hline "، & 18 " & ، \\
\hline $1 / 4800$ & 15 " & $\because$ \\
\hline ". & I 7 " & $\because$ \\
\hline$" \because$ & 18 & " 6 \\
\hline " & 19 " & alive (?) turgid \\
\hline$I / 5600$ & I 8 & dead, flabby \\
\hline " & 19 & . \\
\hline " & $2 I \quad r$ & alive, turgid \\
\hline " & 22 & $\because 4$ \\
\hline$I / 6400$ & 16 & dead, flabby \\
\hline ‘ & I9 " & alive, turgid \\
\hline ‘ & 22 " & i \\
\hline 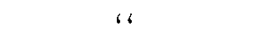 & 23 & " 6 \\
\hline
\end{tabular}

(Begun Feb. I9, I2.00 m.; closed Feb 20, 9. I 5 a.m.)

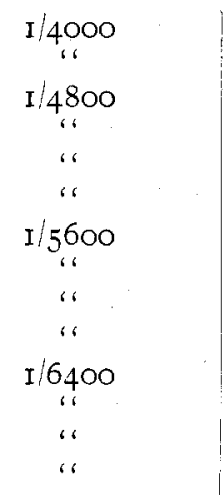

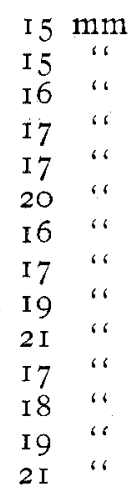

dead, flabby

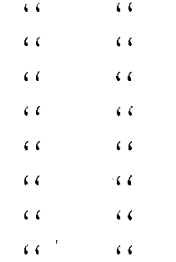

alive, turgid dead, flabby alive, turgid 
(Begun March I 2, 9.30 a.m.; closed March I3, 9.00 a.m.)

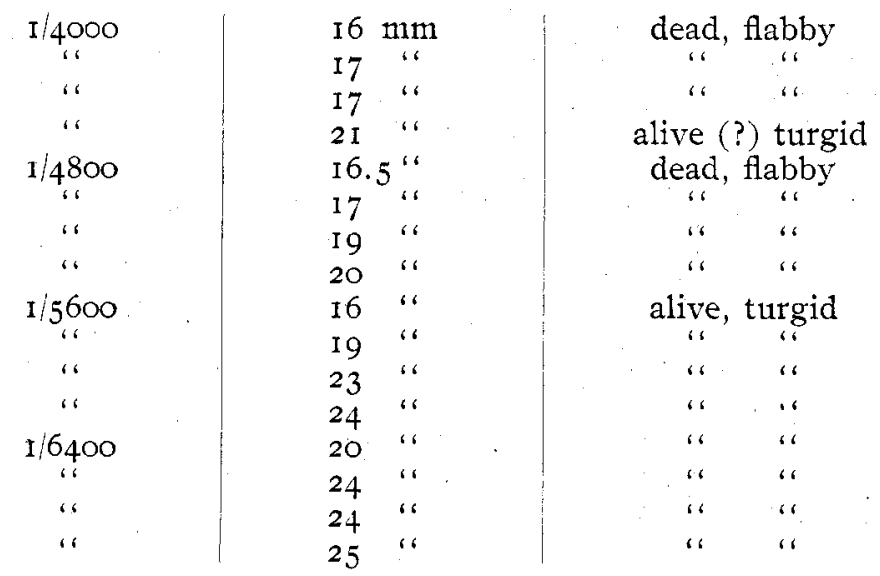

(Begun March I2, 9.30 a.m.; closed March I3, 9.00 a.m.)

\begin{tabular}{|c|c|c|}
\hline $1 / 4000$ & I 5 & $\mathrm{~mm}$ \\
\hline "، & 16 & " \\
\hline ، & I 6 & “ \\
\hline ، & 17 & $\because$ \\
\hline $1 / 4800$ & I7 & " \\
\hline is & 17 & " \\
\hline$\because 6$ & 17 & " \\
\hline " & $2 \mathrm{I}$ & " \\
\hline $1 / 5600$ & 20 & " \\
\hline 16 & 24 & " \\
\hline " & 26 & " \\
\hline ، & 28 & $"$ \\
\hline $1 / 6400$ & I 8 & ، \\
\hline ' & 20 & " \\
\hline " & 20 & "، \\
\hline " & 26 & ، \\
\hline
\end{tabular}

dead, flabby
"،
"،
"،
"،
"،

alive, turgid

"،

16

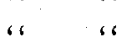

"

a)

" $"$ "

"،

From the third and fourth series in Table I, it appears that the seedlings survive in $n / 5600$ solution. The first series shows that two beans died in the $n / 5600$ solution, while two survived; the second series indicates that only one out of four seedlings survived in the $n / 5600$ solution, and that two out of four survived in the $n / 6400$ solution. From the second series one would conclude that the result for the critical concentration previously found $(n / 6400)$ is about correct; however, the beans used in this 
series were hardly normal in their resisting power, because they were very slow in germinating, the temperature of the laboratory having been rather low at night because of very cold weather. More weight is to be given to the results in the last two series, because the seedlings used were better average specimens. The results in these series and also those in the first series indicate that the previous result $n / 6400$, while not far from correct, is rather low, and that $n / 5600$ is probably the more correct value for the critical concentration.

The solutions of the acid sodium salts were prepared in each case by adding the calculated volume of a standard solution of pure sodium hydroxide to the acid and then diluting to the required volume. Table II gives the results obtained in four series of experiments on acid sodium oxalate.

TABLE II

Acid Sodium Oxalate

(Begun Feb. 20, 2.30 p.m.; closed Feb. 21, 9.I5 a.m.)

\begin{tabular}{|c|c|c|}
\hline $\begin{array}{l}\text { Concentration in } \\
\text { gm. mol. per liter }\end{array}$ & Length & Remarks \\
\hline$I / 2800$ & $\begin{array}{l}\text { I } 6 ~ \\
\text { I } 6\end{array}$ & dead, flabby \\
\hline$I / 3000$ & I6 ، & " \\
\hline ". & I 7 " & "، \\
\hline $1 / 3200$ & I 7 & " $"$ " \\
\hline 4 & I $8 \quad "$ & alive, tip dead \\
\hline $1 / 3600$ & I7 “ & alive, turgid \\
\hline
\end{tabular}

(Begun Feb. 28, 3.30 p.m.; closed March I, 2.00 p.m.)

\begin{tabular}{|c|c|c|}
\hline $1 / 2800$ & I $5 \mathrm{~mm}$ & dead, flabby \\
\hline$I / 3000$ & I5 " & “" \\
\hline "، & & “" \\
\hline$I / 3200$ & I6 " & $"$ \\
\hline & $\begin{array}{l}16.5 " ، \\
17\end{array}$ & alive, turgid" \\
\hline "r & 18 & 16 \\
\hline
\end{tabular}


(Begun Feb. 28, 3.30 p.m. ; closed March I, 2.00 p.m.)

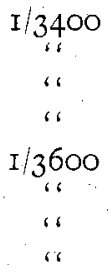

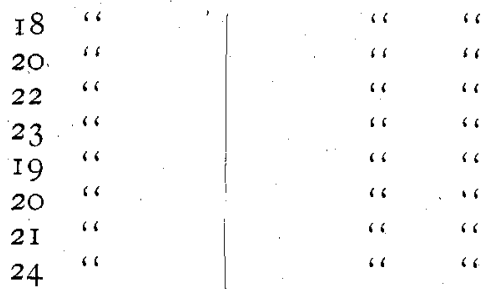

(Begun March 2, I I.co a.m.; closed March 3, 9.40 a.m.)

\begin{tabular}{|c|c|}
\hline $1 / 3000$ & I. 5 \\
\hline ، & $\begin{array}{l}18 \\
20\end{array}$ \\
\hline " & $2 \mathrm{I}$ \\
\hline$I / 3200$ & I 8 \\
\hline & I 8 \\
\hline '، & $2 \mathrm{I}$ \\
\hline " & I 8 \\
\hline $1 / 3400$ & I 7 \\
\hline & 17 \\
\hline " & I 7 \\
\hline " & 22 \\
\hline $\mathrm{I} / 3600$ & I9 \\
\hline " & 20 \\
\hline "، & $2 \mathrm{I}$ \\
\hline " & 22 \\
\hline
\end{tabular}

dead, flabby

alive (?), turgid dead, flabby

" " "

"

" "

alive, turgid

" 4

a)

، "

،

6

(Begun March 9, I0.45 a.m.; closed March IO, 9. I 5 a.m.)

\begin{tabular}{|c|c|c|}
\hline$I / 2800$ & I 6 & $\mathrm{~mm}$ \\
\hline " & I 7 & \\
\hline " & I7 & " \\
\hline " & I 7 & "6 \\
\hline $1 / 3000$ & 16 & "، \\
\hline & I 7 & 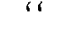 \\
\hline " & 17 & $"$ \\
\hline ؛ & 23 & 8 \\
\hline $1 / 3200$ & I 7 & \\
\hline & I 8 & 6 \\
\hline " & I9 & 6 \\
\hline 6" & I9 & \\
\hline $1 / 3400$ & I 7 & \\
\hline & I9 & \\
\hline 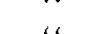 & 20 & \\
\hline 6 & 23 & \\
\hline
\end{tabular}

dead, flabby

$$
\text { "، }
$$

alive, turgid dead, flabby alive, turgid "r is ، . . dead, flabby alive, turgid " " "

The results in Table II show that the concentration in 
which the plants just survive is from $n / 3200$ to $n / 3400 .^{\mathrm{I}}$ Some more hardy plants do survive in the former concentration and, again, less resistant specimens occasionally die in the weaker solution. The concentration $n / 3400$ will be taken as being more nearly the correct value sought.

Four series of tests were made with acid sodium tartrate, the results of which are given in Table III.

TABLE III

Acid Sodium Tartrate

(Begun Jan. 29, I 2.00 m.; closed Jan. 30, I2.00 m.)

\begin{tabular}{|c|c|c|}
\hline $\begin{array}{l}\text { Concentration in } \\
\mathrm{gm} \text {. mol. per liter }\end{array}$ & Length & Remarks \\
\hline $\mathrm{I} / \mathrm{I} 800$ & $20 \mathrm{~mm}$ & dead, flabby \\
\hline & 25 & alive (?), turgid \\
\hline$I / 2000$ & 22 " 22 & dead, flabby \\
\hline $\mathrm{I} / 2200$ & $\begin{array}{l}22 \\
30\end{array}$ & alive turgid \\
\hline " & $3 I ،$ & ‘s \\
\hline$I / 2400$ & 24 & " " " \\
\hline ? & 33 & $\because$ \\
\hline$I / 2600$ & 24 & “ \\
\hline 6 & 26 & " \\
\hline$I / 2800$ & 26 & ra \\
\hline " & 29 '، & '6 \\
\hline
\end{tabular}

(Begun Feb. 28, I I.45 a.m.; closed March I, I2.00 m.)

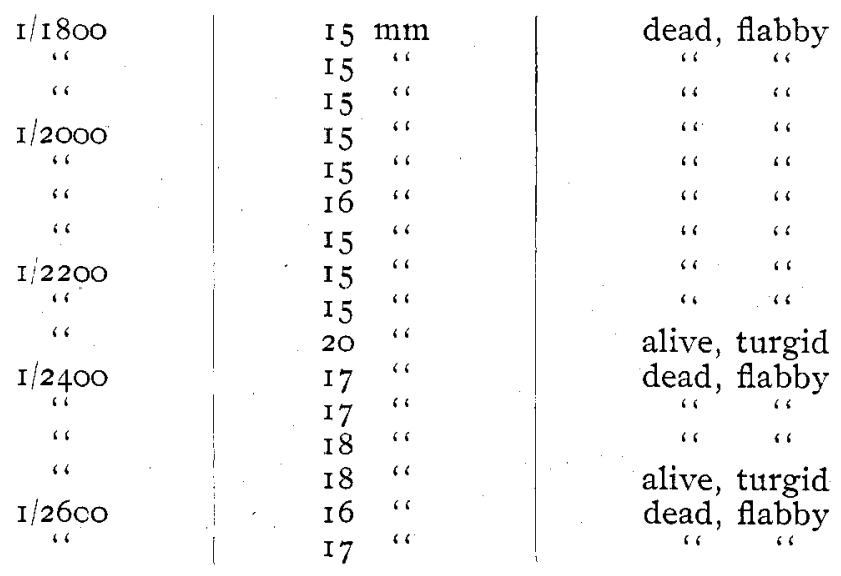

- In this article, the term normal always signifies a solution containing one gram molecule of the substance per liter. 
(Begun March 2; Io.00 a.m.; closed March 3, 9. I 5 a.m.)

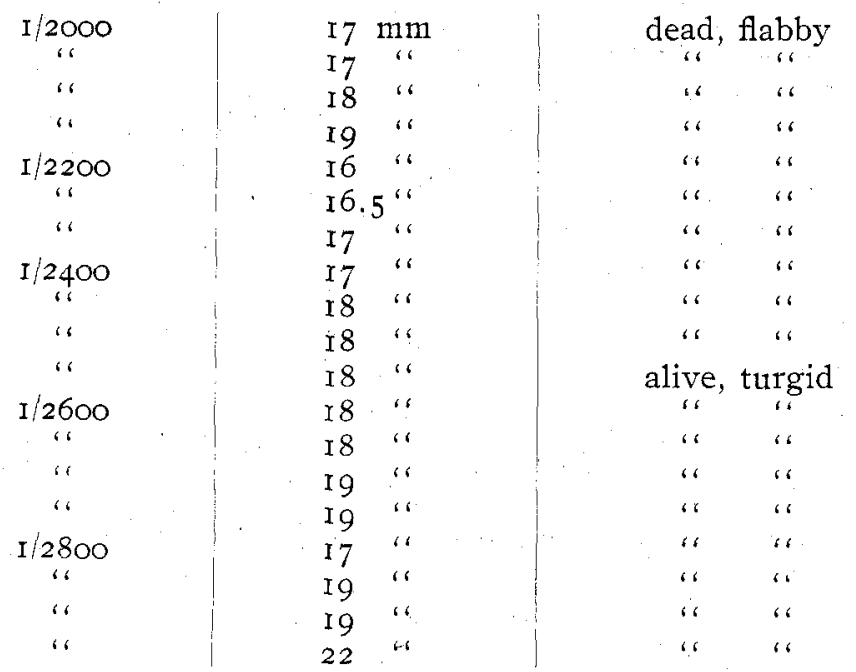

(Begun March 9, I0.00 a.m.; closed March Io, 9.00 a.m.)

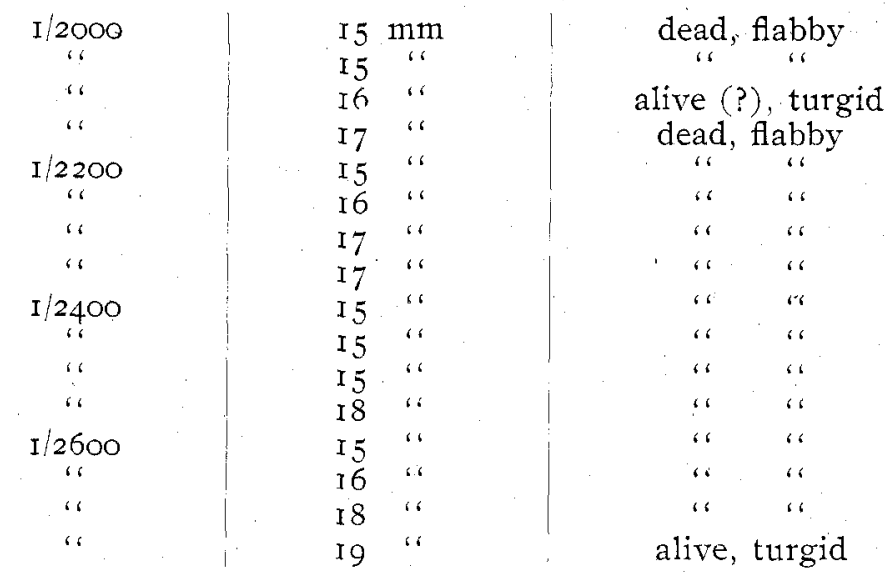

The first series of Table III places the limit at $n / 2200$; according to the second series the seedlings do not survive in the concentration $n / 2600$, while one specimen lived in the $n / 2200$ and one in the $n / 2400$ solutions. Again, according to the third series, the limiting concentration is fairly definitely determined to be $n / 2600$, while the fourth series shows that $n / 2600$ has killed three beans out of four. This the results obtained vary between $n / 2200$ and $n / 2800$. As the concentration in which the beans will just survive is the one sought, $n / 2800$ will 
be the strength used in comparing the toxic action of this salt with the poisonous effects of the other salts investigated.

In the case of acid sodium malate only three series of tests were made; the results of these tests are detailed in Table IV.

TABLE IV

Acid Sodium Malate

(Begun Feb. I2, I0.00 a.m.; closed Feb. I3, 8.40 a.m.)

\begin{tabular}{|c|c|c|}
\hline $\begin{array}{l}\text { Concentration in } \\
\text { gm. mol. per liter }\end{array}$ & Length & Remarks \\
\hline $1 / 300$ & I $5 \mathrm{~mm}^{\prime \prime}$ & dead, flabby \\
\hline $\mathrm{I} / 350$ & $\begin{array}{l}17 \\
16\end{array}$ & " \\
\hline & I 8 " & alive (?), turgid \\
\hline $1 / 400$ & I 5 " & dead, flabby \\
\hline ، & 18 " & $\because 4$ \\
\hline $1 / 450$ & $16.5^{\prime \prime}$ & ". \\
\hline & I7 & “ \\
\hline $\mathrm{I} / 500$ & 15 & ، \\
\hline "، & I 7 & " \\
\hline$I / 600$ & 21 & alive, turgid \\
\hline r & 21 & " \\
\hline
\end{tabular}

(Begun Feb. I4, I I.40 a.m.; closed Feb. I 5, 9.25 a.m.)

\begin{tabular}{|c|c|c|}
\hline$I / 400$ & $19 \mathrm{~mm}$ & dead, flabby \\
\hline & I8 “ & \\
\hline & 2 I & alive, turgid \\
\hline & I9 & dead, flabby \\
\hline & 20 & alive, turgid \\
\hline & I7 & dead, flabby \\
\hline
\end{tabular}

(Begun March 8, 9.25 a.m.; closed March 9, 9.00 a.m.)

\begin{tabular}{|c|c|c|}
\hline $\mathrm{I} / 400$ & $17 \mathrm{~mm}$ & dead, flabby \\
\hline 6 & $17 "$ & " " \\
\hline ، & I 8 & alive, turgid \\
\hline & 22 & ." \\
\hline 4 & 21 & ، \\
\hline "“ & 23 & " \\
\hline ، & 23. & ، \\
\hline I $/ 600$ & 17 & dead, flabby \\
\hline & $2 \mathrm{I}$ & alive, turgid \\
\hline & 22 & \\
\hline 6 & 22 & "، \\
\hline
\end{tabular}


According to the first series, the limiting concentration sought for acid sodium malate is $n / 600$. No definite conclusions can be drawn from the second series. It must be stated in this connection, however, that the specimens used in this series varied more from each other in their development than usual. The seedlings used in the third series were a much better average lot than those employed in either of the two other series; therefore, much more reliance is to be placed on the results recorded in the last series. According to the third series, the concentration in which the seedlings will survive may safely be placed at $n / 500$.

On sodium acid succinate four series of tests were mado. The data obtained are given Table V.

\section{TABLE $\mathrm{V}$}

Acid Sodium Stuccinate

(Begun Feb. IO, I I.00 a.m.; closed Feb. II, IO.00 a.m.)

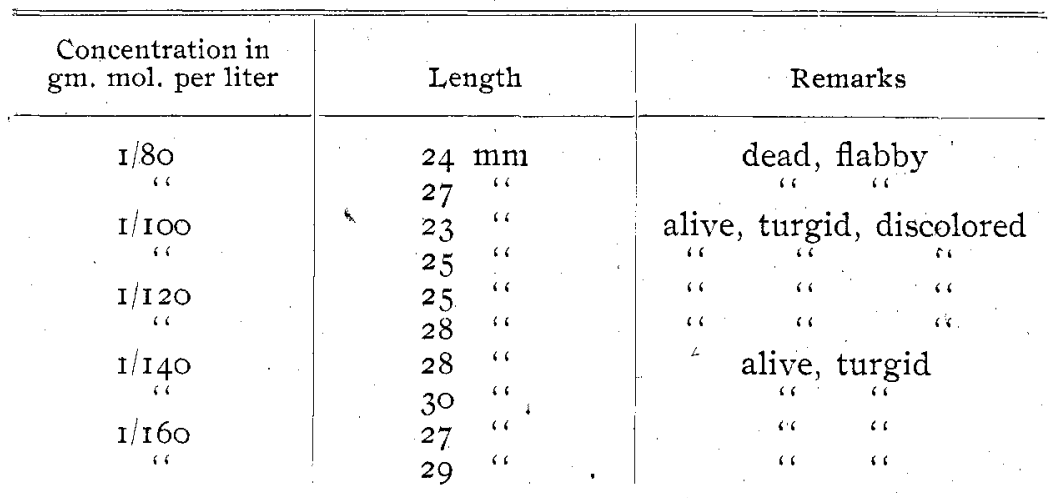

(Begun Feb. I2, Ir.oo a.m.; closed Feb. 13, 8.00 a.m.)

\begin{tabular}{|c|c|c|}
\hline $\mathrm{I} / 80$ & I 5 & $\mathrm{~mm}$ \\
\hline & 24 & " \\
\hline $1 / 100$ & I 5 & 6 \\
\hline "s & 20 & " \\
\hline $\mathrm{I} / \mathrm{I} 20$ & I8 & "، \\
\hline " & 19 & " \\
\hline$I / I 60$ & I6 & "، \\
\hline$\because$ & 17 & $\because$ \\
\hline
\end{tabular}

dead, flabby

alive, turgid

dead, flabby

alive, turgid

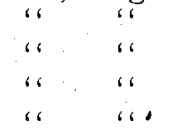


(Begun Feb. 14, 3.30 p.m.; closed Feb. I5, 3.30 p.m.)

$1 / 60$
$1 / 80$
16
$1 / 100$
$1 "$
I/ 20
$1 / 150$
$1 / 6$

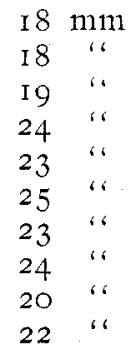

$$
\begin{gathered}
\text { dead, flabby } \\
\text { "، } \\
\text { " } \\
\text { " } \\
\text { ". } \\
\text { alive, turgid } \\
\text { "“ " } \\
\text { alive (tip dead) } \\
\text { alive, turgid }
\end{gathered}
$$

(Begun March 8, 2.20 p.m.; closed March 9, 4.00 p.m.)

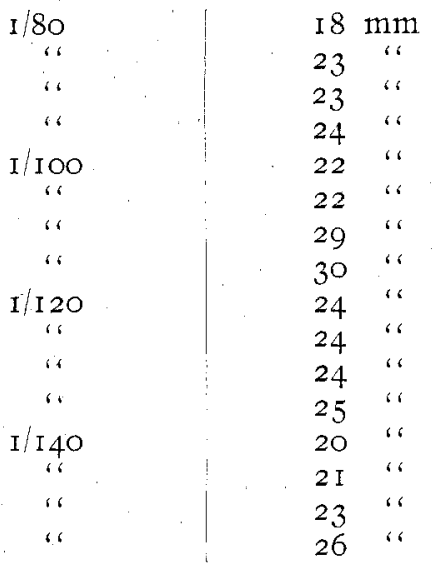

dead dead, flabby

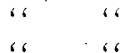

alive, turgid

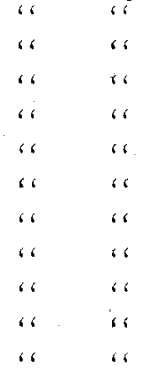

From Table $\mathrm{V}$ it appears that all the seedlings tested survived in the $n / \mathrm{I} 20$ solution. In the first and fourth series, the plants also lived in the $n /$ Ioo solution; but in the third series they were killed by the latter concentration, while in the second series one of the beans died and the other survived. In the comparison to be made hereafter $n / \mathrm{I} 20$ will be used as the concentration in which the seedlings will survive.

Two experiments were performed on mono-sodium citrate. Table VI gives the restils obtained. 


\section{TABLE VI}

\section{Mono-Sodium Citrate}

(Begr11 Jan. 30, 4.00 p.m.; closed Jan. 3I, 11.45 a.m.)

\begin{tabular}{|c|c|c|}
\hline $\begin{array}{l}\text { Concentration in } \\
\text { gm. mol. per liter }\end{array}$ & Length & Remarks \\
\hline $\begin{array}{c}I / 1200 \\
3 / 6\end{array}$ & $\begin{array}{l}\mathrm{I} 6 \mathrm{~mm} \\
\mathrm{I} 7\end{array}$ & $\underset{\text { dead, flabby }}{،}$ \\
\hline \multirow{2}{*}{$\mathrm{I} / \mathbb{I}_{4:}^{400}$} & I 5 & " \\
\hline & I9 & “ \\
\hline \multirow{2}{*}{$1 / 1600$} & 16 & $"$ \\
\hline & 18 & " \\
\hline \multirow{2}{*}{$\mathrm{I} / \mathrm{I} 800$} & $21 "$ & alive, turgid \\
\hline & 22 & " \\
\hline
\end{tabular}

(Begun March 5, 9.30 a.m.; closed March 6, 9.30 a.m.)

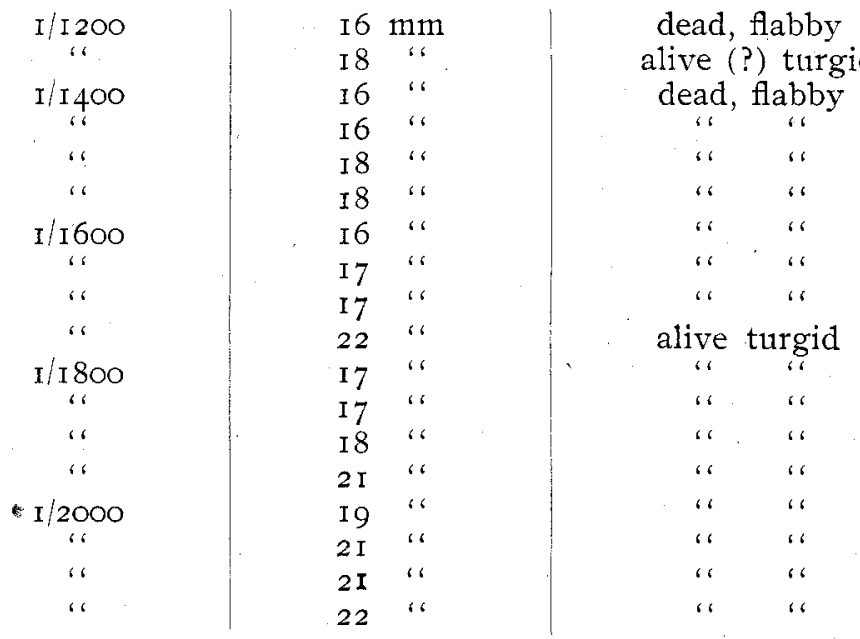

From Table VI it is evident that the critical strength of the solution for mono-sodium citrate is $n / \mathrm{r} 800$, for all the seedlings tested survived in this concentration, while with one exception they died in the $n / 1600$ solution.

The three series of experiments made with di-sodium citrate are recorded in Table VII. In the stronger concentrations used, this salt has the tendency to turn the rootlets brown. 


\section{TABLE VII \\ Di-Sodium Citrate}

(Begun Jan. 30, 4.40 p.m.; closed Jan. 3I, 12.00 m.)

\begin{tabular}{|c|c|c|}
\hline $\begin{array}{l}\text { Concentration in } \\
\mathrm{gm} \text {. mol. per liter }\end{array}$ & Length & Remarks \\
\hline$I / 300$ & $17 \mathrm{~mm}$ & dead, flabby, brown \\
\hline \multirow{2}{*}{$1 / 35^{\circ}$} & I 8 & "، \\
\hline & I6 & ، \\
\hline \multirow{2}{*}{$1 / 400$} & 17 & \\
\hline & 20 & dead, naboy \\
\hline \multirow[t]{2}{*}{$1 / 500$} & I 7 & alive, turgid \\
\hline & $2 \mathrm{I}$ & \\
\hline \multirow{2}{*}{$1 / 600$} & I 5 & \multirow{2}{*}{$\begin{array}{l}\text { accidentally injured } \\
\text { alive, turgid }\end{array}$} \\
\hline & 22 & \\
\hline
\end{tabular}

(Begun Feb. I6, 3.30 p.m.; closed Feb. I7, 12.40 p.m.)

\begin{tabular}{|c|c|c|c|c|c|c|}
\hline $1 / 300$ & & $\mathrm{~nm}$ & \multirow{2}{*}{\multicolumn{4}{|c|}{ 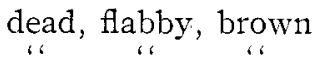 }} \\
\hline & & & & & & \\
\hline \multirow{2}{*}{ I/350 } & I 8 & “ & "، & & & $"$ \\
\hline & 19 & $"$ & \multirow{2}{*}{\multicolumn{4}{|c|}{ alive, turgid }} \\
\hline $1 / 400$ & 20 & "i & & & & \\
\hline & 22 & " & \multicolumn{2}{|c|}{ " } & \multicolumn{2}{|c|}{$"$} \\
\hline & 23 & "6 & \multicolumn{4}{|c|}{ " } \\
\hline & 20 & $"$ & \multirow{2}{*}{\multicolumn{2}{|c|}{$"$ " }} & \multicolumn{2}{|l|}{ " } \\
\hline & 20 & $"$ & \multirow{2}{*}{\multicolumn{2}{|c|}{$\because$}} & \multicolumn{2}{|l|}{ " } \\
\hline " & $2 \mathrm{I}$ & " & & & \multicolumn{2}{|l|}{$"$} \\
\hline "6 & $2 \mathrm{I}$ & ? & & ' & “" & \\
\hline \multirow[t]{2}{*}{$1 / 500$} & 22 & "“ & \multicolumn{4}{|c|}{$"$} \\
\hline & 22 & $"$ & \multicolumn{4}{|c|}{$"$} \\
\hline & 23 & " & \multirow{2}{*}{\multicolumn{4}{|c|}{. }} \\
\hline "6 & 23 & "، & & & & \\
\hline \multirow{2}{*}{$\mathrm{I} / 600$} & 22 & 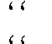 & \multirow{2}{*}{\multicolumn{4}{|c|}{ “ }} \\
\hline & 22 & $u$ & & & & \\
\hline
\end{tabular}

(Begun March 6, 2.00 p.m.; closed March 7, 4.30 p.m.)

\begin{tabular}{|c|c|c|}
\hline $\mathrm{I} / 300$ & I $5 \mathrm{~mm}$ & dead, flabby \\
\hline & I5 & " " \\
\hline & $\begin{array}{l}15 \\
19\end{array}$ & $\begin{array}{l}\text { anve (?) turgid } \\
\text { alive, turgid }\end{array}$ \\
\hline & 19 & "1 16 \\
\hline & 27 & \\
\hline
\end{tabular}


(Begun March 6, 2.00 p.m.; closed March 7, 4.30 p.m.)

\begin{tabular}{|c|c|c|c|}
\hline $\mathrm{I} / 4_{/ 6}^{400}$ & $17 \mathrm{~mm}$. & alive, & turgid \\
\hline ، & 20 & " & . \\
\hline$\because$ & $2 \mathrm{I}$ & ، & ، \\
\hline I $/ 45^{\circ}$ & I9 & " & $"$ \\
\hline & $2 I$ & $"$ & " \\
\hline " & 23 & "، & " \\
\hline " & 24 & " & $"$ \\
\hline I $/ 500$ & I 8 & “ & $"$ \\
\hline & 22 & '، & $\because$ \\
\hline
\end{tabular}

The first series of Table VII would indicate the critical concentration to be $n / 500$; according to the second series it is $n / 400$, while the third series would place it at $n / 35^{\circ}$. As more seedlings were tested in each of the second and third series than in the first, $n / 400$ will be taken as the concentration of di-sodium citrate in which the seedlings will just survive.

The results of the foregoing investigations have been collected in Table VIII, the headings of which give the explanations necessary to understand the table. With the single exception of the value for sodium acid oxalate, the figures of column 4 are taken from Smith's determinations. ${ }^{\mathrm{x}}$

The normal sodium salts of the acids employed in making the acid salts tested in Table VIII have only a very slight toxic action, if any. The toxic effect of the free acids has been previously determined approximately by Kahlenberg and True. ${ }^{2}$ The results that were obtained are collected in Table IX.

While the data in Table IX can at best give only a rough idea between what limits the critical concentration for each acid lies, they do show that the free acids have a highly poisonous effect. A comparison of Table IX with the second column of Table VIII, shows that the acid salts are less toxic than the free acids; but not surprisingly so. The toxicity of acid sodium malate and acid sodium succinate differs more, relatively, from that of malic and succinic acids, respectively, than does the toxic-

\footnotetext{
11. c.
}

21. c. 


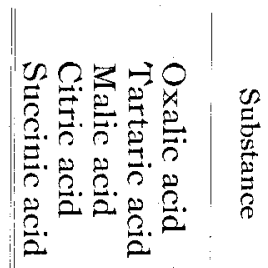

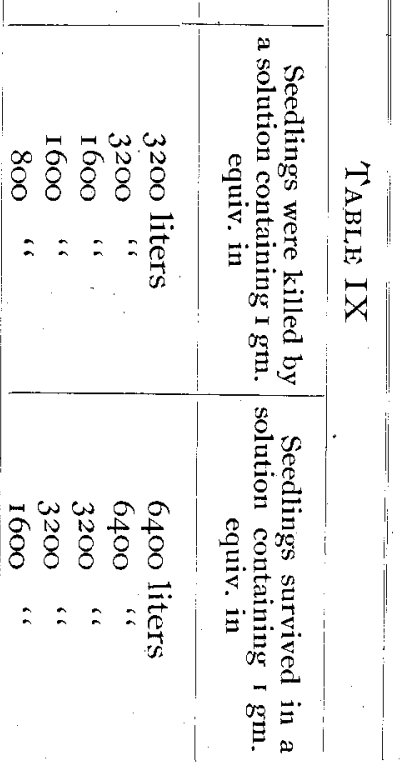

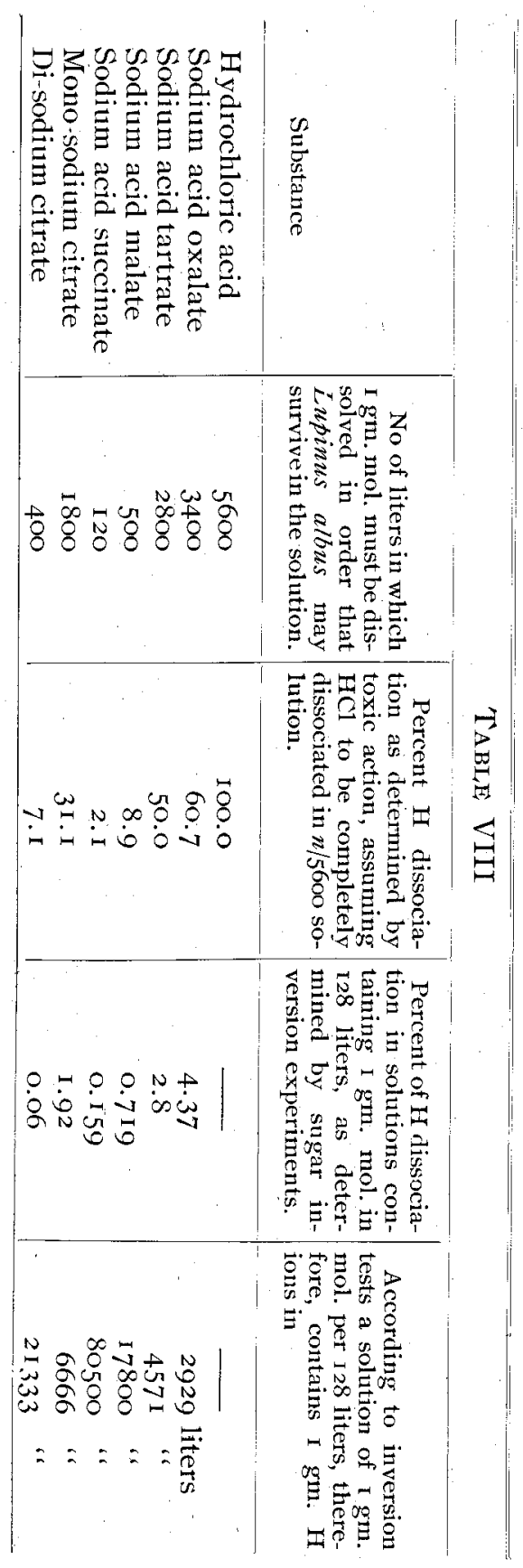


ity of acid sodium oxalate and acid sodium tartrate from the poisonous action of the corresponding free acids.

Heretofore the poisonousaction of the acids has been ascribed mainly to the hydrogen ions present. If it be assumed that the hydrogen ions cause the poisonous effect observed in the case of acid salts, it is evident from the last two columns of Table VIII that, with the single exception of acid sodium oxalate, all the acid salts mentioned ought to permit Lupinus albus to survive in solutions containing I gm. mol. in 128 liters. Now, only acid sodium succinate allows the seedlings to grow in the latter concentration, though according to the fifth column of Table VIII, the plants evidently ought to flourish in concentrations much stronger than $n / \mathrm{r} 20$. For sodium acid oxalate, Trevor found the hydrogen dissociation to be 6.I 3 percent for a solution containing $\mathrm{I} \mathrm{gm}$. mol. in $25^{6}$ liters; this means that $\mathrm{I} \mathrm{gm}$. $\mathrm{H}$-ions would be contained in $4 \mathrm{I} 76$ liters of the latter solution. Since it has been found that the seedlings will survive in a solution of I gm. mol. sodium oxalate in 3400 liters, it is evident that, if the toxicity be due only to the $\mathrm{H}$-ions present, the plants ought to survive in a solution containing I gm. mol. in 256 liters. The great discrepancy between the actual facts and the theory that the toxicity is due to the $\mathrm{H}$-ions is therefore manifest in the case of all these acid salts. This discrepancy is also strikingly shown by a comparison of the third column (of Table VIII) containing the degrees of dissociation, and the fourth column giving the results obtained by the method of sugar inversion. Of course, we here compare solutions of different strengths, but it is not at all probable that the $\mathrm{H}$-dissociation of these acid salts would increase sufficiently with the dilution to harmonize the. results given in the two columns last mentioned. This is evident, for instance, from the case of acid sodium succinate, where the concentrations are nearly comparable.

It will be noted that in general the order of the toxicity of the acid salts is also the order in which they invert sugar, with the single and striking exception that di-sodium citrate inverts sugar much more slowly than a corresponding solution of acid 
sodium succinate, yet the former has a much greater toxic action than the latter.

It is clear that these acid salts are mucl more poisonous than they ought to be, assuming their toxicity to be due to the hydrogen ions only. This really means then that the theory of electrolytic dissociation is unsatisfactory in explaining the toxic action of these acid salts. The true explanation of the poisonous action of these acid salts (and that of acids also) is very likely to be found in the property which they all have in common, namely, in their ability to netutralize basic substances; and of course, this action would depend on the avidity of the acid or acid salt employed. It is evident, however, that this explanation is independent of the theory of electrolytic dissociation. It was found by Kahlenberg that solutions of acid salts also have a much more pronounced sour taste than they ought to have considering their taste to be due solely to the $\mathrm{H}$-ions present, so that the results obtained are in a general way such as might have been expected.

Laboratory of Physical Chemistry, University of Wisconsin, Madison, May ro, 1900.

${ }^{1}$ Jour. Phys. Chem, 4, 33I (I900). 